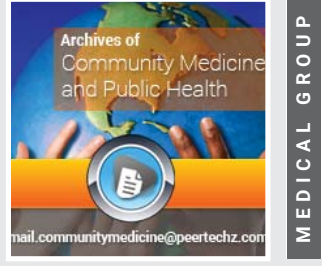

\title{
Spinal Muscular Atrophy - The disease and its treatments
}

\section{Kyra Y. Chen*}

Student at San Dieguito High Academy, San Diego County, California, United States
Received: 25 June, 2021

Accepted: 16 July, 2021

Published: 17 July, 2021

*Corresponding author: Kyra Y. Chen, Student at San Dieguito High Academy, San Diego County, California, United States, E-mail: kyrachen04@gmail.com

https://www.peertechzpublications.com

\section{Check for updates}

\section{Introduction}

Less than a decade ago, patients diagnosed with Spinal Muscular Atrophy (SMA) had no treatments other than pulmonary, gastrointestinal, and orthopedic care. These palliative treatments were focused on managing symptoms and did not address the cause of the disease itself. Now, there are several FDA (U.S. Food and Drug Administration) approved drugs to treat SMA, which can stop or slow disease progression. In order to discuss the development of treatments for patients with SMA, the disease must first be explained in detail.

\section{The disease}

Spinal muscular atrophy is a rare neuromuscular disease which causes the degeneration of motor neurons and progressive muscle wasting [1]. It is caused by the deletion of the Survival Motor Neuron 1 (SMN 1) gene on chromosome number 5. The SMN 1 gene codes for the SMN protein, which is critical to the health and survival of motor neurons in the spinal cord and brainstem. Another gene, SMN2, also can code for the SMN protein, but has a 6 base pair change in exon 7 which results in the majority of SMN2 transcripts lacking exon 7 [2]. SMN2 is referred to as a disease modifying gene because the more copies a person with SMA has, the milder the disease. Without SMN protein, the motor neurons die, leading to loss of motor function. This can result in poor head control, difficulties swallowing, scoliosis, and joint contracture.

SMA is an autosomal recessive disease, meaning that both parents must have at least one copy of the mutation (Figure 1). The gene frequency is reported to be approximately 0.02 , meaning that 1 person out of every 50 people carries the gene. However, the actual frequency of the disease is closer to 1 in 10,000 [3]. Unlike most other inherited diseases, SMA is present in all races and genders.

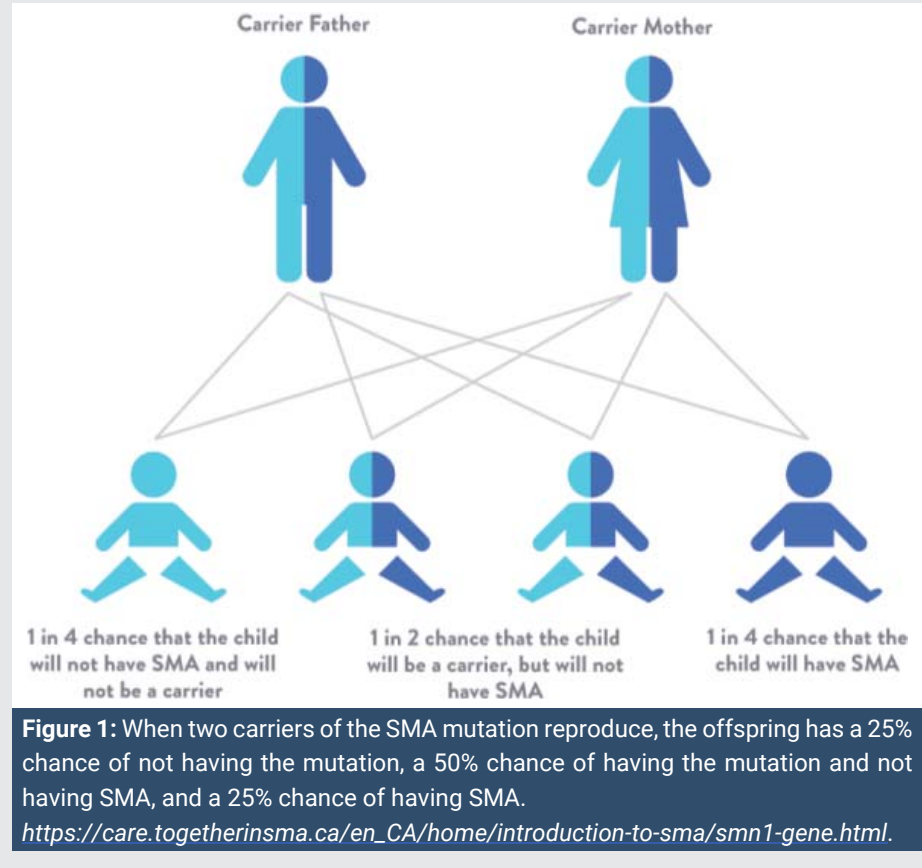

\section{Phenotypes}

Although it is usually diagnosed in infancy or early childhood, people with SMA can start showing symptoms before birth or even in adulthood. There are five types of SMA [4], classified by age of onset and maximal achieved motor abilities.

\section{Type 0}

SMA type 0 is the rarest and most severe form of the condition, with symptoms being evident before birth. With only one copy of the SMN2 gene, affected fetuses show less movement in the womb and are resultantly born with joint contractures and extremely weak muscle tone. Usually, they rarely survive past infancy [5]. 


\section{Type 1}

SMA type 1, also known as Werdnig-Hoffman Disease [6], is the most common form of the condition. Symptoms typically become evident within the first few months of life, and usually appear quickly and unexpectedly. Children with this type have two copies of SM2, they never learn to sit unsupported and cannot control their head movements. Without treatment or respiratory support, these babies rarely survive past two years of age; with proper respiratory support, milder cases are known to survive into adulthood.

\section{Type 2}

In SMA type 2, the onset of weakness is between 6 to 18 months of life. Children with this type have three copies of SMN2, and were capable of sitting without support at sometime in their life, but never learned to walk independently. Additional symptoms include tremors, scoliosis, and respiratory muscle weakness. Although disease progression varies hugely in patients, most are able to survive into adulthood but have reduced life expectancies.

\section{Type 3}

SMA type 3, also known as Kugelberg-Welander disease [7], manifests itself after 18 months of age. Children have three to four copies of SMN2 and are able to walk, albeit with some difficulty. Many patients lose this ability after several years. It is rarer for respiratory involvement, and the life expectancy is normal or close to normal.

\section{Type 4}

Another rare form, SMA type 4 begins in early adulthood. These individuals have 4 or more copies of SMN2. Symptoms include gradual weakening of leg muscles, tremors, and mild breathing problems. Life expectancy is normal.

\section{Treatments}

There is no complete cure for SMA. Before the development of drugs to treat the disease, treatment consisted of physical and occupational therapy, assistive devices, and nutritional care. However, there are now three different FDA-approved drugs for SMA, with four more in clinical trials [7].

\section{Spinraza (nusinersen)}

The companies behind spinraza: Spinraza was developed by Ionis Pharmaceuticals (formerly known as Isis Pharmaceuticals) in collaboration with Biogen. Ionis, a Carlsbad-based company, was founded in 1989 with a goal to commercialize antisense therapy [8]. It has had 5 drugs approved by the FDA, with 3 currently on the market [9]. Biogen is a Cambridge-based company which specializes in the discovery, development, and delivery of treatments for neurological diseases to patients around the world. It has had 13 drugs approved by the FDA [10].

However, the initial discovery of Spinraza was a collaborative effort between Ionis and Drs. Adrian Krainer and Yimin Hua at Cold Spring Harbor Laboratories (CSHL) [11], who published their findings on using a bifunctional Antisense Oligonucleotide (ASO) to enhance SMN2 exon 7 inclusion [12]. This caught the attention of Frank Bennett, Ph.D, Senior Vice President of Research at Ionis, and he reached out to Dr. Krainer to discuss a potential collaboration to advance the findings.

\section{How it works}

The drug uses Antisense Oligonucleotides (ASOs) to selectively redirect alternative splicing and increase SMN2 exon 7 inclusion, thus increasing the amount of functional SMN protein produced (Figure 2). It is delivered via an intrathecal injection, which is an injection into the spinal canal or into the subarachnoid space so that it reaches the cerebrospinal fluid [13].

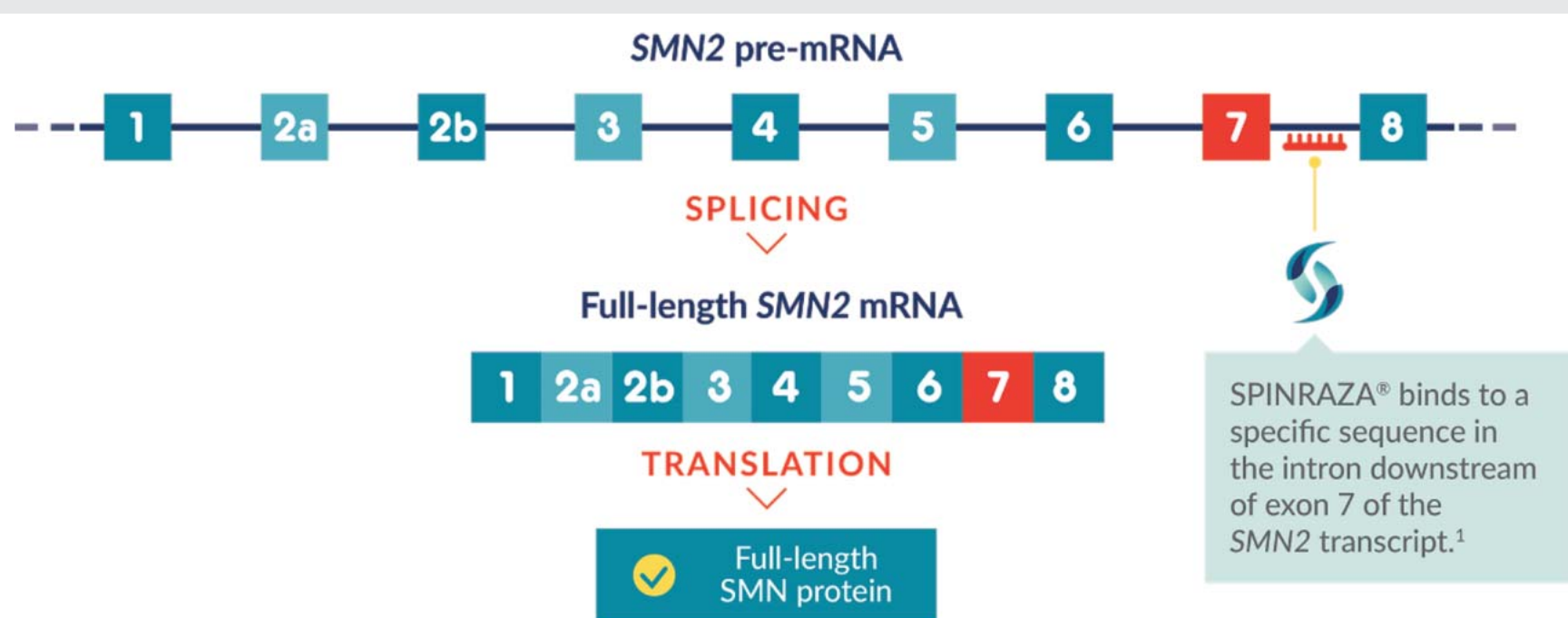

SMN2=survival motor neuron 2; mRNA=messenger ribonucleic acid

Citation: Chen KY (2021) Spinal Muscular Atrophy - The disease and its treatments. Arch Community Med Public Health 7(2): 138-141. 


\section{The approval process}

First, Ionis and CSHL researchers screened multiple ASOs to define the optimal region on SMN2 pre-mRNA for ASO's effect on splicing. In preclinical studies, the treated mice had significant increases in exon 7 inclusion and experienced delayed loss of motor neurons, preserved neuromuscular junctions, improved muscle physiology, and increased survival [12].

Ionis then filed an Investigational New Drug application with the FDA and advanced Spinraza into clinical development.

As Ionis had limited clinical experience in neurological diseases and dosing drugs intrathecally, and this would be the first time they would evaluate an antisense drug in infants, it was necessary that they find the right company to collaborate with. In 2012, Ionis and Biogen entered into an exclusive, worldwide collaboration to develop and commercialize Spinraza [14].

Several different controlled and open-label studies were initiated, including a Phase 3 study known as ENDEAR. The ENDEAR study was a randomized, double-blind, shamprocedure controlled 13-month study which evaluated SPINRAZA in 121 patients with infantile-onset SMA. The study met its primary endpoint for the interim analysis in August of 2016, in which infants treated with Spinraza showed a statistically significant improvement in the primary endpoint in comparison to the control group [15].

Biogen completed Spinraza's New Drug Application in September of 2016, and the regulatory applications were accepted by the FDA and EMA (European Medicines Agency) in October. In December 2016, Spinraza was approved by the FDA to treat all ages and types of SMA [16] and it was approved in the EU in June of 2017 [17].

\section{Additional treatments}

\section{Zolgensma (onasemnogene abeparvovec-xioi):} Zolgensma, marketed by Novartis Gene Therapies, is a gene replacement therapy delivered by an intravenous (IV) infusion. It is also an SMN-enhancing therapy and works by using a virus, AAV9, to carry the replacement SMN1 gene into the body. Zolgensma was approved by the FDA in May 2019 for patients with all forms and types of SMA who are under 2 years of age at the time of dosing [18].

Evrysdi (risdiplam): Evrysdi, marketed by Genentech, is a liquid oral medication which helps the SMN2 gene produce more functional SMN protein. It is the first oral medication approved by the FDA to treat SMA. Similar to Spinraza, it modifies the splicing of SMN2 messenger RNA. Evrysdi was approved by the FDA in August 2020 for adults and children two months of age or older [19].

\section{Conclusion}

In summary, significant advancements have been made in the treatment of spinal muscular atrophy. In the past, there were no drugs and children with severe forms of the disease rarely survived past infancy or childhood. With the advancement of novel technologies, however, there are now several drugs on the market for patients of varying ages and disease phenotypes. All are SMN-enhancing, with two targeting the splicing of SMN2 RNA, and one using a viral vector to deliver a normal copy of SMN1 to motor neurons.

It is possible that these drugs, due to their different mechanisms, can be used in combination to an even greater benefit. In fact, Biogen has started a global phase 4 study examining the efficacy of a combination of Zolgensma and Spinraza [20]. Hopefully with such combination therapies in addition to the existing therapies, SMA can become a condition which can simply be lived with and managed, and patients can lead almost normal lives.

\section{References}

1. Spinal Muscular Atrophy: MedlinePlus Genetics. MedlinePlus, U.S. National Library of Medicine. Link: https://bit.ly/3hHkHjd

2. Monani UR, Lorson CL, Parsons DW, Prior TW, Androphy EJ, et al. (1999) Single Nucleotide Difference That Alters Splicing Patterns Distinguishes the SMA Gene SMN1 From the Copy Gene SMN2. Hum Mol Genet 8: 1177-1183. Link: https://bit.ly/3xMrBJB

3. About Spinal Muscular Atrophy (SMA). Cure SMA. Link: https://bit.ly/3escdux

4. Waldrop MA, Elsheikh BH (2020) Spinal Muscular Atrophy in the Treatmen Era. Neurol Clin 38: 505-518. Link: https://bit.ly/36GGkKg

5. Diseases - SMA - Types Of Overview. Muscular Dystrophy Association. Link: https://bit.ly/3xXcRHS

6. Spinal Muscular Atrophy Fact Sheet. National Institute of Neurological Disorders and Stroke, U.S. Department of Health and Human Services. Link: https://bit.ly/3inqw40

7. Treatment for Spinal Muscular Atrophy (SMA). Cure SMA. Link https://bit.ly/36Jx2xf

8. Antisense Technology. Ionis Pharmaceuticals, Inc. Link: https://bit.ly/3wM0oFA

9. Our Medicines. Ionis Pharmaceuticals, Inc. Link: https://bit.ly/3rgluLI

10. Product Portfolio

11. The Discovery of Spinraza. Cure SMA 2018

12. Hua Y, Vickers TA, Okunola HL, Bennett CF, Krainer AR (2008) Antisense Masking of an HnRNP A1/A2 Intronic Splicing Silencer Corrects SMN2 Splicing in Transgenic Mice. Am J Hum Genet 82: 834-848. Link: https://bit.ly/36FJQEJ

13. Spinraza. Cure SMA. Link: https://bit.ly/3kmvls8

14. Biogen Idec and Isis Pharmaceuticals Announce Global Collaboration for Antisense Program Targeting Spinal Muscular Atrophy. Biogen. Link: Link: https://bit.ly/2USwTVD

15. Early-Onset SMA (Type 1): SPINRAZA® (Nusinersen). Official Patient Site. Link: https://bit.ly/3kqLpia

16. Commissioner (2016) Office of the. FDA Approves First Drug for Spinal Muscular Atrophy. U.S. Food and Drug Administration, FDA. Link: https://bit.ly/3wlmLMf 
17. Anonymous. Spinraza. European Medicines Agency. Link: https://bit.ly/36CRxvz

18. Zolgensma. Cure SMA. Link: https://bit.ly/3wJTvoq
19. Evrysdi. Cure SMA. Link: https://bit.ly/3z4NaFM

20. Marta F (2020) Spinraza-Zolgensma Combination Well-Tolerated in Children with SMA. Link: https://bit.ly/2TdAwEW
Discover a bigger Impact and Visibility of your article publication with

Peertechz Publications

Highlights

* Signatory publisher of ORCID

* Signatory Publisher of DORA (San Francisco Declaration on Research Assessment)

* Articles archived in worlds' renowned service providers such as Portico, CNKI, AGRIS, TDNet, Base (Bielefeld University Library), CrossRef, Scilit, J-Gate etc.

* Journals indexed in ICMJE, SHERPA/ROMEO, Google Scholar etc.

* OAI-PMH (Open Archives Initiative Protocol for Metadata Harvesting)

* Dedicated Editorial Board for every journal

* Accurate and rapid peer-review process

* Increased citations of published articles through promotions

* Reduced timeline for article publication

Submit your articles and experience a new surge in publication services (https://www.peertechz.com/submission).

Peertechz journals wishes everlasting success in your every endeavours.

Copyright: $\odot 2021$ Chen KY. This is an open-access article distributed under the terms of the Creative Commons Attribution License, which permits unrestricted use, distribution, and reproduction in any medium, provided the original author and source are credited. 